\title{
Silvio Zavala y la historia de América. Un juego de escalas
}

\begin{abstract}
This article explores de History of America Program, sponsored by the Panamerican Institute of Geography and History, and led by Silvio Zavala, in order to assess the possibilities and limitations of writing a history of the American continent. It is based primarily on Zavala's own writings, published in the Revista de Historia de América.
\end{abstract}

Key words: Silvio Zavala, history of America, scale.

\section{RESUMEN}

Este texto explora el Programa de Historia de América, auspiciado por el Instituto Panamericano de Geografía e Historia y liderado por Silvio Zavala, para ponderar los alcances y limitaciones de escribir una historia del continente americano. El texto se finca sobre todo en los textos publicados del propio Zavala, principalmente en la Revista de Historia de América.

Palabras clave: Silvio Zavala, historia de América, escala.

* Doctora en Historia, Centro de Estudios Históricos, El Colegio de México, correo electrónico: epani@colmex.mx 
E 2018 marca el 80 aniversario de la fundación de la Revista de Historia de América, publicación políglota — publica textos en español, francés, inglés y portugués-, que ambicionaba reseñar el desarrollo histórico del continente, apegándose a parámetros científicos del más alto nivel. Dirigida por el joven historiador mexicano Silvio Zavala, la revista era auspiciada por el Instituto Panamericano de Geografía e Historia, que había sido fundado en 1928 para promover la circulación de estudios sobre la geografía, cartografía, historia y geofísica del continente americano. El Instituto había dado estabilidad y permanencia a una de las iniciativas más originales y fértiles del organismo multilateral continental que, en distintas encarnaciones - de la Oficina Comercial de las Repúblicas Americanas, establecida en 1890, a la Organización de Estados Americanos, fundada en 1948, pasando por la Unión Panamericana (1910-1948) — había promovido el panamericanismo: el intercambio — sobre todo a través de conferencias y publicaciones- de conocimientos científicos y jurídicos, de información económica, de iniciativas para promover la salud pública, la educación, la construcción de infraestructura y las buenas prácticas administrativas, que debían contribuir a la consolidación y optimización de las maquinarias de gobierno y al bienestar de las sociedades de los países americanos como comunidad de naciones jóvenes, republicanas y americanas, con intereses compartidos y distintos a los de la Vieja Europa. ${ }^{1}$

La aspiración a escribir una "historia de América" no era nueva. En 1932, Herbert E. Bolton, presidente de la American Historical Association (AHA), había convocado a sus colegas a escribir la "epopeya" del "hemisferio occidental". ${ }^{2}$ A Bolton lo motivaban la filosofía - la historia no podía seguir engendrando ciudadanos "chovinistas", ignorantes, convencidos del excepcionalismo de su experiencia nacional—, la ambición historiográfica - la mirada continental revelaría que cada historia nacional no era "sino una hebra que formaba parte de un hilo" más sustancial- y el pragmatismo - la importancia creciente de las relaciones interamericanas exigía que en cada país del continente se tuviera "una mejor comprensión de la historia y cultura de todos". ${ }^{3}$ No obstante, su invitación no tuvo más eco que el rechazo de algunos y la indiferencia de la mayoría. ${ }^{4}$

En cambio, la Revista de Historia de América ofrecía menos un programa que un espacio para la historia continental. A diferencia de la propuesta de Bolton, que a pesar del prestigio de la AHA — la organización gremial de historiadores más potente de la América anglófona - no dejaba de ser una

\footnotetext{
Marichal, México.

Bolton, "The Epic of Greater America", pp. 448-474.

Ibid., pp. 448-449.

Véanse las críticas acerbas contenidas en Hanke, ed., Do the Americas. Las investigaciones del propio Bolton, en cambio, transformaron el campo de la historia de las fronteras en Estados Unidos. Hurtado, "Bolton and Turner".
} 
iniciativa individual, la de la Revista tenía una base institucional y, por lo tanto, vuelo político y arraigo burocrático. Los vínculos con la Unión Panamericana sugerían que, como sucedería posteriormente con la Historia Atlántica y la Organización del Tratado del Atlántico Norte (OTAN), ${ }^{5}$ se lanzaba una iniciativa académica para apuntalar un proyecto político, dotándolo de densidad histórica.

Sin embargo, si el panamericanismo, como movimiento, como espacio para la política exterior y como conjunto de instituciones, era a menudo objeto de crítica por sus desequilibrios internos de poder y la influencia desmedida que se suponía ejercía Estados Unidos, los editores de la Revista consideraron que el prestigio de los académicos involucrados y la "finalidad puramente científica" del instituto que la sufragaba garantizaban su calidad y objetividad. ${ }^{6}$ La publicación representaba además un esfuerzo entre otros acometidos por académicos e intelectuales, durante el periodo de entreguerras, que apostaron a la colaboración internacional para promover la paz, el bienestar y el entendimiento entre los pueblos. ${ }^{7}$

¿Qué posibilidades y oportunidades encierra la historia de América? ¿Qué lugar ocupó en la visión historiográfica de Silvio Zavala, que como investigador, profesor, editor y constructor de instituciones es uno de los principales artífices de la historiografía académica en México? Quienes estudian el pasado llevan prácticamente un siglo — desde que Lucien Febvre condenara la "historia sierva" en 1919 y hasta el día de hoy, en que la "historia global" ha despertado gran entusiasmo - reclamando se emancipe a la historia del estado-nación, a pesar del papel central que ha desempeñado éste en el desarrollo de aquélla: desde el último cuarto del siglo XIX se consolidaron la biografía de la nación como objeto preferente de la investigación histórica, y la enseñanza de la "historia patria" como instrumento para inculcar conciencia cívica y nacionalismo. ${ }^{8}$ La importancia del papel político y pedagógico de la historia nacional ha representado, consistentemente, si no un obstáculo para el desarrollo y la difusión de otros marcos para leer el pasado y difundir la memoria, sí el que estos esquemas alternativos siempre tengan que competir con el nacional.

No obstante, conscientes de que la nación no representa el marco natural y exclusivo de prácticamente ningún proceso histórico, que éstos se mal entienden

$5 \quad$ Bailyn, Atlantic History, pp. 3-57.

6 Para una visión crítica de las relaciones panamericanas, véase Salvatore, Imágenes; un análisis más complejo de las posibilidades del foro panamericano se plasma en Carrillo Reveles, México. Figuraron, entre los colaboradores y asesores de la Revista Rafael Heliodoro Valle, Ernesto de la Torre, Rafael Altamira, Marcel Bataillon, Agustín Millares Carlo, Ricardo Levene, Arthur P. Whitaker, J. Ignacio Rubio Mañe y Richard Konetzke. Heredia Correa, "Revista de Historia de América".

Véase, por ejemplo Pita González, Educar.

Ferro, Comment. 
cuando se manipulan para caber en un territorio inventado como nacional por razones políticas, y que las fronteras a menudo cercenan el panorama de su desarrollo y alcance, los profesionales de la disciplina han buscado construir otros espacios que historiar: la localidad y la región, los imperios, las regiones fronterizas, los circuitos transoceánicos y "transnacionales", los continentes. Sin embargo, si la historia de Europa — quizá también la de África, y, en principio, la de Oceanía - se han consolidado como objetos tanto de investigación como de docencia, no sucede lo mismo con otros conglomerados territoriales que organizan la geografía del globo.

Los intereses de investigación del principal promotor de la "Historia de América" nunca estuvieron restringidos por la camisa de fuerza del espacio nacional. Zavala, como especialista de la época colonial —que no "virreinal", pues no se limitó nunca a la Nueva España, empeñándose, desde un principio, en revelar los resortes de un imperio estructurado por el derecho, la economía global, las instituciones monárquicas, y el trabajo y los intereses individuales - ${ }^{9}$ la nación le resultaba anacrónica, o se veía ampliamente rebasada por la lógica de los temas que investigaba: el corpus jurisdiccional, la filosofía política y las redes de intercambio de la monarquía hispana. Pero si ésta representa, a todas luces, una entidad histórica transnacional y transoceánica coherente, ¿podía decirse lo mismo del continente americano a lo largo del tiempo? En este texto, pretendemos reseñar -inevitablemente de forma superficial - los esfuerzos que realizó Zavala, durante décadas, por que se escribiera una historia de América, con la esperanza de que este análisis nos sugiera algunas respuestas a estas interrogantes.

Durante años, Zavala desplegó una energía notable para promover institucionalmente la historia continental, y para concretarla, tanto en una obra historiográfica, dirigida a especialistas, como en un programa docente que se esperaba influyera sobre la forma en que se enseñaba historia de Alaska a la Patagonia. La Revista de Historia de América formó parte de este esfuerzo, ligado, desde el principio, con el panamericanismo. Don Silvio y el connotado hispanoamericanista Lewis Hanke, primer director de la sección hispana de la Biblioteca del Congreso en Washington, D.C., lograron convencer al ingeniero Pedro Sánchez, presidente del Instituto Panamericano de Geografía e Historia, de la utilidad de la empresa, a pesar de que, según el geógrafo, fueran los historiadores "tercos y pendencieros". ${ }^{10} \mathrm{El}$ otro pilar del proyecto americanista, más ambicioso, fue el Programa de Historia de América, que promoviera la Organización de Estados Americanos.

La Revista fue, sobre todo en cuanto a la forma, un proyecto innovador. Se dirigía a un público a un tiempo más amplio y más selecto que el que habían conformado los profesores universitarios, en su enorme mayoría 
estadounidenses, que escucharon el discurso de Bolton. Se trataba de la comunidad de estudiosos que, en América Latina, buscaban profesionalizarse y sentar los reales de la historia como disciplina académica y científica. La Revista se abocaría a publicar investigaciones, información de archivo, y "descubrimientos de documento (...) más allá" de las fronteras políticas de cada país, que debían ser especialmente útiles a los profesionales de la historia que estudiaban los que habían sido los territorios de Ultramar de la corona española, dada la uniformidad del régimen de gobierno y de los principios de la cultura, así como el interesante paralelismo y divergencias concretas de las instituciones jurídicas y económicas. En el periodo de la independencia la semejanza de las fuentes inspiradoras de doctrinas y de los intereses aliados o enemigos [...] Los Estados Unidos de Norteamérica y el Brasil, aunque independientes de la fuerza unificadora de España, presentan atractivos temas comunes de historia de límites, relaciones comerciales e influencias del espíritu. ${ }^{11}$

No obstante, la solidez de la propuesta metodológica, de su apertura y de las buenas intenciones de los editores, una breve incursión en los índices de la Revista sugiere que ésta no logró aglutinar los estudios de los distintos espacios americanos dentro de un objeto de estudio coherente. Poco hizo por disipar la tensión entre "Nuestra América" y la otra - la que nos era ajena, ya por parecernos hostil, ya por sernos desconocida. Desde los primeros años del siglo Xx, en el seno de las Conferencias Panamericanas que habían marcado el rumbo de la política cultural continental, se había promovido, como prioridad, el "atesorar" la herencia cultural hispanoamericana. ${ }^{12}$ Dentro de la misma línea, los artículos sobre la América hispana, y en especial aquellos que se ocupan del periodo colonial, dominan abrumadoramente lo publicado en la Revista.

De vez en cuando se incluía algún artículo sobre Estados Unidos —once hasta 1975, normalmente vinculados a problemáticas hispanoamericanas. Aparecen también textos sobre el Caribe británico (cuatro) o francéscontribuyendo Hénock Trouillot en casi todos los artículos sobre Saint Domingue / Haití (cinco). La historia de Canadá, estado que se había integrado a la Organización de Estados Americanos apenas en 1962, como observador, fue objeto de seis artículos. Excepcionalmente, y por encargo, hubo números que se centraron en las naciones de la América extranjera: en 1952 se publicó un dossier con cuatro artículos sobre la "nueva era" de la historiografía estadounidense. En 1968 se compilaron cinco artículos para marcar el centenario de la confederación canadiense. Éste se había celebrado el año anterior, pero había sido desplazado, en las páginas de la Revista, por otra conmemoración: la del fin de la Intervención francesa en México.

\footnotetext{
"Propósitos", pp. v-vi.

Esther Aillón Soria, "Política", p. 149.
} 
El proyecto continental de Don Silvio se sistematizó y adquirió mayor enjundia al crearse la Comisión de Historia del IPGH en 1946. Se le encomendó la "supervisión científica" de la Revista y del Boletín Bibliográfico de Antropología Americana, cuya difusión debía esbozar "una visión de conjunta de las experiencias humanas de América, sin menoscabo de las diferencias históricas, mas atendiendo también a los intereses comunes". ${ }^{13}$ En 1950, esta Comisión, ya bajo los auspicios de la Organización de Estados Americanos - que había remplazado a la Unión Panamericana recién dos años antes-, estableció el Programa de Historia de América, al frente del cual estaría Zavala. El proyecto, que recibió financiamiento de la Fundación Rockefeller, pretendía se elaborara "un esbozo de una historia general o de varias historias de todas las Américas", que sirviera para el desarrollo de cursos generales y avanzados sobre historia de América, y para estimular, por medio de la colaboración entre especialistas y por encima de los nacionalismos bibliográficos, que enfrentaran los desafíos y resolvieran los problemas que surgirían con la elaboración del primer esbozo. ${ }^{14}$

El Programa de Historia de América movilizó a un número importante de "distinguidos especialistas" a lo largo y ancho del continente, historiadores, pero también arqueólogos y antropólogos, cuyos saberes se consideraron esenciales para reconstruir la historia de la América precolombina, llamada "indígena", aunque, como insistieron sus autores - cuya visión abarcadora los distinguió quienes se abocaron a otras épocas_-, la problemática de los pueblos indígenas moldeaba de manera trascendental también los periodos colonial e independiente, tanto como la actualidad del continente. ${ }^{15}$ El programa generó una importante producción editorial que incluyó, además de avances parciales, nutridas listas bibliográficas e índices razonados para auxiliar a los investigadores y a los profesores que se disponían a impartir cursos de historia americana.

El sistema de trabajo, concebido por la ordenada - hubo quien la describió, sin malicia, como "dominante" _ cabeza de Silvio Zavala preveía que se avanzara simultáneamente en distintos frentes. Con la orientación de un coordinador por cada época estudiada -Pedro Armillas, Silvio Zavala y Charles C. Griffin - cada grupo de estudiosos abordaría uno de los grandes periodos en los que se había dividido el pasado continental: el "indígena", la época colonial y el que se describiría como el "periodo nacional", siguiendo lineamientos previamente acordados. De forma individual y en algunos casos colectivamente, los investigadores — que, más allá de las líneas generales

\footnotetext{
"Recapitulación”, p. vi.

Zavala, "International Collaboration", pp. 284-288.

Pedro Armillas en "El Programa de Historia de América”, p. 144.

Harold E. Davis, de American University, en "El programa de Historia de América", p. 214, utilizó el adjetivo en inglés commanding.
} 
establecidas, gozaban de "entera libertad" - redactaron y publicaron sus avances de investigación: textos, en su mayoría, centrados en regiones y periodos particulares. Otros analizaron algún aspecto peculiar de las sociedades americanas del pasado, como por ejemplo, los "precedentes medievales" de la colonización americana que estudió el belga Charles Verlinden, o los efectos de la guerra de Siete Años en el continente, que redactara John W. Caughey. Se cubrirían entonces, progresiva y sistemáticamente, distintos espacios a lo largo de diferentes momentos.

Aparecieron así, en la década de los cincuenta, entre los libros avocados al "Periodo indígena", el libro Los orígenes, de Hannah M. Worthington, y trabajos que exploraban la historia anterior al contacto con el Viejo Mundo de regiones geomorfológicas —el área ártica, el altiplano andino, la zona circuncaribe-, de zonas culturales —Mesoamérica-, de territorios identificados anacrónicamente con los países que los ocupaban a mediados del siglo xx —Estados Unidos y Canadá, Guianas, Brasil- y de unidades de estudio que, suponemos, se armaron en respuesta a la austeridad presupuestal y gracias a la buena relación entre los autores, como el texto sobre Mesoamérica y Colombia (Suplementos) (1953) que editaron Ignacio Bernal y Gerardo Reichel-Dolmatoff.

Quienes investigaban el periodo colonial hicieron una primera entrega a principios de la década de 1950, abordando las grandes regiones de los imperios español, portugués y británico. El periodo nacional resultó el más problemático. Sólo se redactaron cuatro esquemas detallados, aunque "prácticamente independientes" el uno del otro. En un primer momento — por falta de recursos_-, no se publicó sino el trabajo de María del Carmen Velázquez sobre México, Centroamérica y las Antillas. En años subsecuentes aparecerían los trabajos sobre América del Sur (Eugenio Pereira Salas, 1957) y Brasil (Américo Jacobina Lacombe, 1956). Al parecer, no se publicó el libro de Enrique Ortega Ricaurte sobre lo que fue la Gran Colombia. ${ }^{17}$

El ambicioso programa contemplaba tanto la investigación al más alto nivel y a escala continental como la enseñanza de la materia de historia de América en todos los países americanos, desde la secundaria hasta la universidad. Provocó debates intensos entre colaboradores y lectores, y fue objeto de críticas sistemáticas en el marco de reuniones periódicas (La Habana en 1953; México y Nueva York — como sede de la reunión anual del American Historical Association en 1954-; México en 1955; Cuenca, Ecuador, en 1957), mismos que fueron recogidos por la Revista. Colaboradores

17 "El programa de Historia de América", pp. 133-134. Para 1955, primer corte de caja del proyecto, se habían publicado once títulos sobre el periodo indígena, cinco sobre el periodo colonial (Brasil, Suramérica, Hispanoamérica septentrional y media, Estados Unidos, y el libro de Verlinden) y uno sobre el periodo nacional. "The Problem of American History in the National Period”, en "El programa de Historia de América", pp. 172-180. 
y lectores identificaron problemas de contenido, de metodología y alcance, de filosofía y estilo. Hubo quien deploró que faltara lo que no estaba y que no se diera suficiente importancia a lo que al opinante más le interesaba: Brasil resultaba "la Cenicienta" de la historiografía americanista — así lo atestiguan también los índices de la RHA-; los indígenas del norte del continente no recibían la atención que merecían. Otros apuntaron que hacía falta involucrar a otros especialistas - economistas, sociólogos, geógrafos, estudiosos de la literatura, la música y el arte-y que había que deshacerse de los "colaboradores que no colaboraban", sobre todo cuando no atendían las prescripciones de los comentaristas. ${ }^{18}$

Algunos de los historiadores involucrados se confesaron impotentes ante el desafío de armar, paralelamente a sus enjundiosas pesquisas, una propuesta educativa cuyos "problemas didácticos independientes" rebasaban su "capacidad como investigadores y profesores de enseñanza superior". ${ }^{19}$ Varios comentaristas consideraron que la enorme tarea de arrear a unos nada dóciles académicos desperdigados por el continente no rendía frutos de similar magnitud: como escribiera J.H. Parry, titular de la cátedra Gardiner de "Historia y Asuntos Oceánicos" en la Universidad de Harvard, el trabajo de Zavala resultaba ser un "tour de force, una masa de información y de ideas, ordenada y equilibrada con simetría, de gran valor e interés" para los interesados en cualquier aspecto de la historia americana. Sin embargo, no había "prácticamente ninguna narrativa, ningún hilo conductor del desarrollo". Se sacrificaban "consideraciones de significado" en aras de mayor armonía en el texto. La conclusión del historiador británico, misma que admitía no poder defender con argumentos precisos, era que la explicación histórica, en su mejor versión, no podía ser sino un "logro intensamente personal", y tendría que ser la obra de un historiador que, además de ser "un estudioso, un prodigio de erudición y entendimiento", tuviera algo de poeta. ${ }^{20}$

Sin embargo, la crítica más sustancial al Programa giró en torno a la posibilidad de historiar a "América". La existencia misma de ésta como entidad parecía dudosa, dado que el continente constituía "una unidad geográfica solamente desde el punto de vista de su aislamiento casi completo del Viejo Mundo, cuna de la humanidad". ${ }^{21}$ La palabra "europeo" no era un "término meramente geográfico", sino la expresión de una cultura, religión

18 J.H. Parry; Waldo B. Leland; Robert N. Burr y Roland D. Hussey, en "El programa de Historia de América", p. 189; p. 209; p. 192; p. 173.

19 Pedro Armillas en "El programa de Historia de América", p. 147. Véase también el comentario de Robert N. Burr y Roland D. Hussey, quienes admitieron no haber organizado satisfactoriamente sus cursos de historia del continente en la Universidad de California. "El programa de Historia de América", pp. 195-196.

20 "El programa de Historia de América", pp. 190-191.

$21 \quad$ Armillas en "El programa de Historia de América", p. 137. 
e historia compartidas. Reflejaba un legado milenario de interacciones constantes y potentes. Se afirmó que unos contactos similares, repetidos y formativos, estaban ausentes de la historia de las naciones americanas, hasta que la "preeminencia política y económica de Estados Unidos" llevara, en el pasado reciente, a los pueblos del continente a reaccionar de manera "enérgica y contenciosa" a las acciones de unos y otros. ${ }^{22}$

Por su parte, quienes creyeron que era viable el proyecto de escribir una historia de América disintieron sobre lo que debía apuntalar el guion básico del programa. Algunos, como el jesuita estadounidense John Francis Bannon, afirmaron que la historia de América era parte del desarrollo de la civilización occidental: las "ideas, ideales, cultura, religión y complejos americanos" eran todos occidentales: lo demás no eran sino "accidentes". ${ }^{23}$ Los profesores Burr y Hussey, especialistas en historia moderna y contemporánea, consideraron en cambio que las referencias centrales del programa debían ser las "manifestaciones" más importantes del excepcionalismo continental: el "sentimiento americano de apartamiento": las "experiencias comunes" de migración, la apertura de fronteras, la lucha en "contra de los indios y el medio ambiente", la rebelión en contra del dominio europeo; debían subrayarse las doctrinas "americanas" sobre los derechos a la emigración, de los neutrales, de naturalización, de igualdad entre los estados, y la fe en los congresos internacionales para la resolución de disputas. ${ }^{24}$

Dada la escala del proyecto, el número de colegas involucrados — que, a decir de don Silvio, incluyó un número estándar de quienes hicieron lo que quisieron y no lo que se les encargó, distinguiéndose entre los insubordinados los que se ocupaban de la "etapa nacional"-, las dificultades implícitas en una empresa continental, interdisciplinaria y multilingüe, en un momento en el que, sin internet ni correo electrónico, tanto la comunicación como la movilidad implicaban una inversión considerable de tiempo y dinero, además de la severidad de las rondas de lectura crítica, evaluación y comentarios, es difícil imaginar el tiempo, trabajo y energía síquica y emocional que exigió su coordinación. No obstante, en la entrevista que le hizo Peter Bakewell a principios de 1981, Zavala se refirió sólo vagamente al Programa, describiéndolo como un producto de la "vena internacionalista" que había distinguido a la Comisión de Historia del Instituto Panamericano y cuyos rastros, apuntó, sobrevivían aún, cuarenta años después, en la Revista de Historia de América. ${ }^{25}$

Así, esa historia de América que se proyectó a finales de los años treinta, que debía ser más que la suma de sus partes, no logró concretarse. Incluso uno

22 J.H. Parry en "El programa de Historia de América", p. 187.

23 J.F. Bannon, en "El programa de Historia de América", pp. 210-211.

24 Burr y Hussey en "El programa de Historia de América”, pp. 199-200.

25 Zavala, “An Interview”, p. 559. 
de los productos más acabados del proyecto, el Programa de la Historia de América en la época colonial (1961) de la autoría del propio Zavala, se quedó corto, según escribió un evaluador. En las páginas de la American Historical Review, Stanley Stein afirmaba que, a pesar de sus virtudes - la presentación de un amplio panorama que "los historiadores de América Latina habían desatendido durante un largo tiempo", el análisis de la construcción de culturas coloniales particulares en las "provincias americanas", y el reconocimiento tanto de la importancia de las aportaciones africanas y asiáticas como de los contactos intercoloniales en la constitución de un pasado americano-, el texto resultaba desbalagado y excesivamente esquemático. Sobre todo, frustraba las expectativas del lector, pues carecía de la penetración y de la maestría en el oficio que habían caracterizado los estudios indianos del historiador mexicano. ${ }^{26}$ Algunas de las críticas de Stein se solventarían en la obra, mucho más extensa y acabada, El mundo americano en la época colonial, que publicó Zavala, en dos volúmenes, en 1967.

El proyecto de la historia de América enfrentó desafíos inmensos, tanto prácticos como conceptuales y metodológicos. Esto quizá explica, en gran parte, que se quedara trunco. Considero, sin embargo, que algo tuvo que ver en esto, también, la concepción que el coordinador tenía del quehacer del historiador. Al echarse a andar el proyecto, hubo quien - ¿puede especularse que el también hiperactivo Leopoldo Zea? - alegó que el punto de partida de una historia continental debía ser el estudio de "la unidad de valores de los pueblos de América". Los historiadores no podían avanzar hasta que el filósofo "estuviera listo para guiarlos". ${ }^{27}$ Este supuesto se fincaba, en opinión de Zavala, en un error: esta convicción a priori era precisamente la debilidad de las historias generales de América publicadas hasta entonces. Las "excelentes cabezas" que habían abonado el campo no habían partido de la observación, sino de una "declaración de fe", de una postura filosófica, sobre la unidad o diversidad del hemisferio occidental, y, en un segundo tiempo, sobre el origen europeo o americano de dicha unidad o diversidad.

El historiador, en cambio, argüía Zavala, no podía partir de un "veredicto plano" sobre las características supuestamente compartidas por las naciones americanas: homogeneidad y heterogeneidad podían convivir, y subrayaba que coincidencias y diferencias podían tener orígenes diversos, seguir direcciones distintas y cambiar en el tiempo. ${ }^{28}$ A principios de la década de 1950, la coordinación del Programa le permitiría afirmar

la conveniencia de rehuir de afirmaciones rotundas o monolíticas sobre la unidad o la diversidad en la historia de América. Es preferible guardar la flexibilidad

26 Stein, "The Colonial Period in the History of the New World by Silvio Zavala and Max Savelle," The American Historical Review, 68: 3, 1963, pp. 757-758.

27 Zavala, "International", pp. 284-285.

28 Zavala, “A General View”, pp. 912-913. 
de juicio que permita hacerse cargo de la pluralidad de los fenómenos y de sus mudanzas temporales. ${ }^{29}$

La historia general de América, entonces, no existía para ser escarbada y puesta en valor porque ahí estaba la masa continental, incluso por quienes de buena fe querían dotar a los organismos de cooperación multilateral de un pedigrí histórico, y asegurar el financiamiento de megaproyectos internacionales. Hay fenómenos y procesos históricos que se desarrollaron en un marco continental - incluso transoceánico- y dentro de éste deben ser analizados, como demostró la amplísima obra de Zavala sobre el mundo indiano, o su trabajo, más acotado, sobre la competencia imperial por el continente. ${ }^{30}$ Es también el caso, quizá irónicamente, de la historia de América como "invención", como construcción de un imaginario de "Nuevo Mundo", como espacio para la utopía, la colonización y la explotación que formulara en 1958 el supuesto gran rival historiográfico de Zavala, Edmundo O’Gorman, quien fuera también uno de los críticos más vehementes de la historia americana de Bolton. ${ }^{31}$

En un texto en el que cuestionaba la solidez de los cimientos metodológicos de la "historia regional" pensada como disciplina, Manuel Miño advertía sobre los peligros de inventar "líneas de investigación" para justificar el hecho de que en el fondo no vamos a tratar de hablar y decir todo sobre todo". Los historiadores están obligados, concluía, a reflexionar menos sobre el por qué y el para qué que sobre el "cómo y el con qué construir el conocimiento histórico". ${ }^{32}$ Incluso, siendo responsable de un ambicioso proyecto de investigación, de escala indócil, Zavala rehuyó de generalidades románticas y conjeturas apriorísticas. En un momento en que, embelesados con lo transnacional y lo global, los historiadores los vemos no como cristales calibrados para percibir ciertas cosas, sino como perspectivas que deben abarcarlo todo, es sano retomar la postura de Zavala. Toca al historiador rastrear - que no asumir - las coincidencias y conexiones, tensiones y diferencias que constituyen a un espacio en un objeto cuya historia vale la pena contar.

\section{Bibliografía}

Bailyn, Bernard, Atlantic History: Concept and Contours, Cambridge, Harvard University Press, 2005.

\footnotetext{
"El programa de Historia de América", p. 159.

Zavala, "Rivalidades imperiales".

O'Gorman, La invención de América; "Do the Americas".

Miño, “Existe la historia regional?"
} 
Bolton, Herbert E., "The Epic of Greater America”, American Historical Review, vol. 8, no. 3, 1933, pp. 448-474.

Carrillo Reveles, Veremundo, México en la Unión de las Repúblicas Americanas: el panamericanismo y la política exterior mexicana, 1889-1942, tesis doctor en Historia, El Colegio de México, 2018.

Ferro, Marc, Comment on raconte l'histoire aux enfants: á travers le monde entier, París, Payot, 1981.

Hanke, Lewis, "Experiencias con Silvio Zavala, 1933-1949: algunos recuerdos al azar", Historia Mexicana, vol. 38, no. 4, 1989, pp. 601-607.

Heredia Correa, Roberto, "Revista de Historia de América. Índice General, 19381962”, Historia Mexicana, vol. 18, núm. 4, 1969, p. 627-628.

Hurtado, Alberto L., "Bolton and Turner: The Borderlands and American Exceptionalism”, Western Historical Quarterly, vol. 44, no. 1, 2013, pp. 4-20.

Marichal, Carlos, México y las conferencias panamericanas, 1889-1938: antecedentes de la globalización, Secretaría de Relaciones Exteriores, México, 2002.

Miño, Manuel, “¿Existe la historia regional?”, Historia Mexicana, vol. 51, núm. 4, 2002, pp. 867-897.

O'Gorman, Edmundo, "Do the Americas Have a Common History", en Lewis Hanke, ed., Do the Americas have a Common History? A Critique of the Bolton Theory, Nueva York, Knopf, 1962, pp. 103-140.

O'Gorman, Edmundo, La invención de América: investigación acerca de la estructura histórica del Nuevo Mundo y del sentido de su devenir, México, Fondo de Cultura Económica, 1984.

Pita González, Alexandra, Educar para la paz. México y la cooperación intelectual internacional, 1922-1948, Universidad de Colima, Secretaría de Relaciones Exteriores, México, 2014.

"El programa de Historia de América: Introducciones y comentarios", Revista de Historia de América, núm. 39, 1955, pp. 133-214.

"Propósitos", Revista de Historia de América, núm. 1, 1938, pp. v-vi.

"Recapitulación”, Revista de Historia de América, núm. 25, 1948, pp. v-vii.

Salvatore, Ricardo, Imágenes de un imperio. Estados Unidos y las formas de representación de América Latina, Buenos Aires, Sudamericana, 2006.

Stein, Stanley J., "The Colonial Period in the History of the New World by Silvio Zavala and Max Savelle", The American Historical Review, vol. 68, núm. 3, 1963, pp. 757-758

Zavala, Silvio, "International Collaboration in the History of America", Comparative Studies in Society and History, vol. I, núm. 3, 1959, pp. 284-288.

"A General View of the Colonial History of the New World", American Historical Review, núm. 66, 1961, pp. 913-929.

, "Rivalidades imperiales en el Nuevo Mundo", Historia Mexicana, vol. 12, núm. 3, 1963, pp. 325-339. 
Zavala, Silvio, Peter Bakewell, Dolores Gutiérrez Mills, "An Interview with Silvio Zavala", The Hispanic American Historical Review, vol. 62, núm. 4, 1982, pp. 553-568. 